La Paz, Madrid, Spain; ${ }^{4}$ Cardiff University, Cardiff, United Kingdom; ${ }^{5}$ Axial Spondyloarthritis International Federation (ASIF), London, Spain; ${ }^{6}$ Cyprus League Against Rheumatism, Nicosia, Cyprus; ${ }^{7}$ Novartis Pharma AG, Basel, Switzerland; ${ }^{8}$ Charité - Universitätsmedizin Berlin, Berlin, Germany; ${ }^{9}$ German Rheumatism Research Centre, Berlin, Germany

Background: Axial Spondyloarthritis (axSpA) is associated with a high degree of functional limitation in daily life activities. However, few studies have evaluated the social and family burden from the patient's perspective.

Objectives: To describe the impact of axSpA on social and family life since disease onset, and the associated PROs.

Methods: Data from 2,846 unselected patients of the European Map of Axial Spondyloarthritis (EMAS) study through an online survey (2017-2018) across 13 European countries were analysed. The impact of axSpA on social and family life were assessed through four PROs: i) Impact on relationships with the spouse, family, friends, neighbours, and work colleagues since disease onset ( 5 point Likert scale; 1 "much better" - 5 "much worse"; ii) Frequency of social activities including outings to bars/restaurants, cinema/theatre/ museums, practising sports, travel/excursions, and intimate relations since disease onset (5 point Likert scale; 1 "much more" - 5 "much less"); iii) Adaptations made to cope with axSpA since disease onset (yes/no question); iv) The degree of functional limitation in 18 daily activities (3 point Likert scale). Self-reported BASDAI (0-10), spinal stiffness (3-12), functional limitation (0-54), and psychological distress (GHQ-12) were analysed using Pearson's correlation comparing the impact on relationships and frequency of social activities since disease onset.

Results: Among 2,846 participants, mean age was 43.9 years, $61.3 \%$ were female, $48.1 \%$ had a university degree. The greatest impact on relationships (sum of 'worse' and 'much worse') since disease onset were those with work-colleagues $(44.5 \%)$, friends $(35.6 \%)$, and spouse $(30.4 \%)$. Sport was the activity they reduced the most since disease onset $(64.2 \%)$, followed by travel/ excursions (57.3\%) and intimate relationships (56.4\%) (Fig. 1). 55.5\% had purchased comfortable shoes $(\mathrm{N}=2748)$ and $43.9 \%$ had made adaptations to their workplace $(N=2651)$. For those who reported their level of functional limitation in daily activities, the greatest limitations were in physical exercise $(85.5 \%)$, cleaning the house $(84.4 \%)$ and using stairs $(79.2 \%)$ (Fig. 2). In the correlation analysis, BASDAI, spinal stiffness, functional limitation, GHQ-12 were associated with a worsening in all of relationships and social activities ( $p$ $<0.001$ ) (Table 1)

Table 1. Pearson's correlation between social and family life changes and PROs

\begin{tabular}{|c|c|c|c|c|}
\hline $\begin{array}{l}\text { Relationships: } 1 \text { much better }-5 \text { much } \\
\text { worse }\end{array}$ & BASDAI & $\begin{array}{l}\text { Spinal } \\
\text { Stiffness }\end{array}$ & $\begin{array}{l}\text { Functional } \\
\text { Limitation }\end{array}$ & $\begin{array}{c}\text { GHQ- } \\
12\end{array}$ \\
\hline Spouse & $0.157^{\star}$ & $0.130^{\star}$ & $0.167^{\star}$ & $0.258^{*}$ \\
\hline Family & $0.162^{*}$ & $0.133^{*}$ & $0.138^{*}$ & $0.206^{*}$ \\
\hline Friends & $0.211^{\star}$ & $0.173^{\star}$ & $0.180^{\star}$ & $0.282^{*}$ \\
\hline Neighbours & $0.210^{*}$ & $0.165^{\star}$ & $0.112^{\star}$ & $0.229^{*}$ \\
\hline Work colleagues & $0.229^{*}$ & $0.153^{*}$ & $0.213^{*}$ & $0.334^{*}$ \\
\hline \multicolumn{5}{|c|}{ Frequency activities: 1 much more -5 much less } \\
\hline Bars / restaurants & $0.261^{*}$ & $0.246^{\star}$ & $0.314^{*}$ & $0.316^{*}$ \\
\hline Cinemas / theatres / museums & $0.291^{*}$ & $0.243^{*}$ & $0.299^{*}$ & $0.338^{*}$ \\
\hline Do sports & $0.271^{*}$ & $0.213^{\star}$ & $0.240^{*}$ & $0.242^{*}$ \\
\hline Travel / excursions & $0.308^{\star}$ & $0.218^{*}$ & $0.307^{\star}$ & $0.362^{*}$ \\
\hline Intimate relations & $0.284^{*}$ & $0.254^{\star}$ & $0.288^{*}$ & $0.321^{*}$ \\
\hline
\end{tabular}

${ }^{\bar{*} p<0.001}$

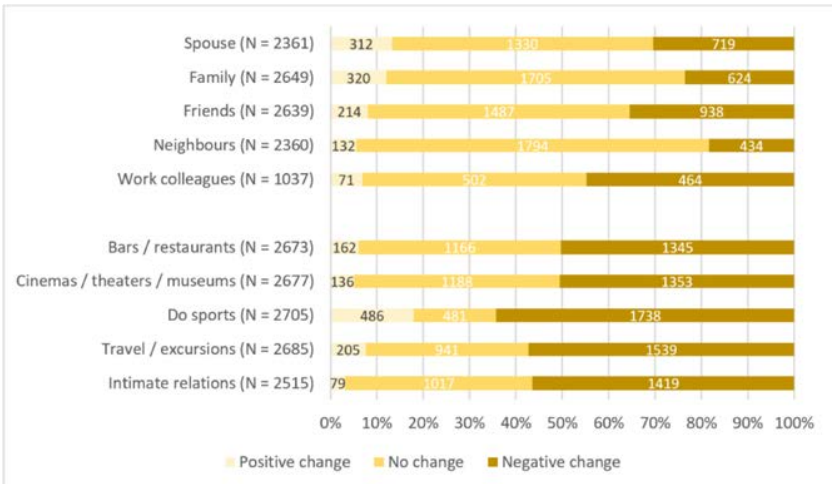

Figure 1. Reported social and family live changes since disease outset

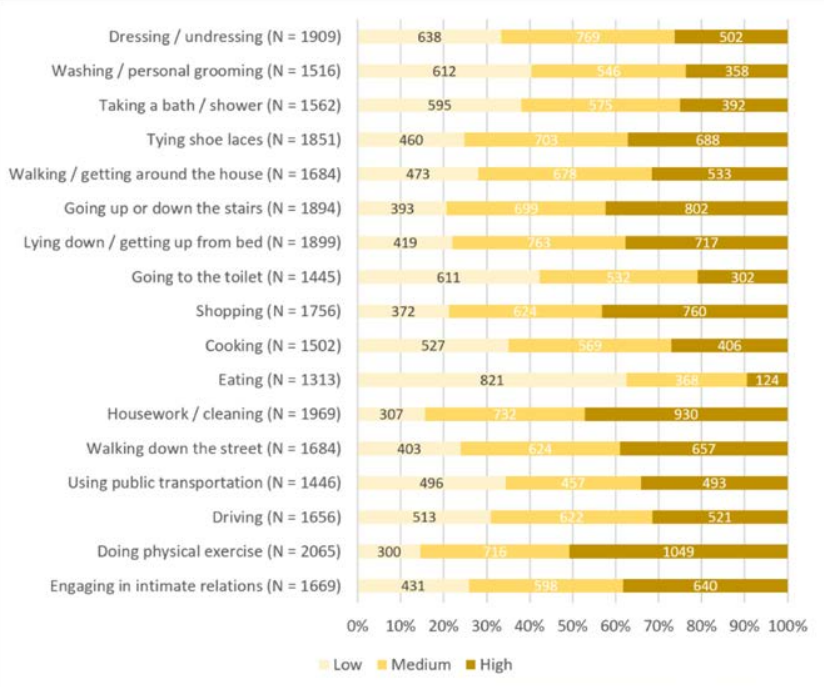

Figure 2. Reported level of functional limitation in daily live activities

Conclusion: For most participants the onset of axSpA marked the worsening of personal relationships in different areas, as well as the reduction of social, leisure, and entertainment activities.

Acknowledgments: Funded by Novartis Pharma AG

Disclosure of Interests: Marco Garrido-Cumbrera: None declared, Victoria Navarro-Compán Consultant of: Abbvie, Lilly, Novartis, Pfizer, UCB, Speakers bureau: AbbVie, MSD, Lilly, Novartis, Pfizer, UCB, Christine Bundy Grant/ research support from: Has received unrelated honoraria from Abbvie, Celgene, Janssen, Lilly, Novartis, and Pfizer., Raj Mahapatra: None declared, Souzi Makri: None declared, Sergio Sanz-Gómez: None declared, Laura Christen: None declared, Carlos Jesús Delgado-Domínguez: None declared, Denis Poddubnyy Grant/research support from: AbbVie, MSD, Novartis, and Pfizer, Consultant of: AbbVie, Bristol-Myers Squibb, Eli Lilly, MSD, Novartis, Pfizer, Roche, UCB, Speakers bureau: AbbVie, Bristol-Myers Squibb, Eli Lilly, MSD, Novartis, Pfizer Roche, UCB

DOI: 10.1136/annrheumdis-2020-eular.4293

\section{SAT0375 ASSESSMENT OF WELL-BEING IN EARLY AXIAL SPONDYLOARTHRITIS; 5-YEAR LONGITUDINAL DATA FROM THE DESIR COHORT.}

$\underline{\text { F. Hirano }}^{1}$, D. Van der Heijde ${ }^{1}$, F. A. Van Gaalen ${ }^{1}$, R. B. M. Landewée, ${ }^{2,}$,

C. Gaujoux-Viala 4 , S. Ramiro ${ }^{1,3} .{ }^{1}$ LUMC, Leiden, Netherlands; ${ }^{2} A U M C$,

Amsterdam, Netherlands; ${ }^{3}$ Zuyderland MC, Heerlen, Netherlands; ${ }^{4}$ Nîmes University Hospital, Nîmes, France

Background: A framework has been proposed to explain which disease outcomes impact quality of life or well-being in patients with axSpA; this was based on cross-sectional data and patients with radiographic axSpA. ${ }^{1}$

Objectives: To investigate the determinants of patient's well-being over time and the influence of contextual factors on these relationships in patients with early axSpA.

Methods: Five-year data from DESIR, a cohort of early axSpA, were analysed. Clinical data were collected every 6 months up to 2 years and annually thereafter. X-rays and MRI of the spine and SIJ were performed at baseline, 2 , and 5 years. The outcome was BAS-G, the patient's global assessment of the disease impact on well-being. Generalized estimating equations (GEE) were used to test the relationship between potential explanatory variables from 5 domains (disease activity, physical function, spinal mobility, structural damage, spinal and SIJ inflammation) and BAS-G over 5 years. Longitudinal relationships were analysed using an autoregressive GEE model. Contextual factors (patient's educational level, gender and age) were tested as potential effect modifiers or confounders.

Results: A total of 708 patients were included, mean age 33.7 (SD 8.6) years, $46 \%$ male, $41 \%$ lower educated. Higher scores of the individual questions of BASDAl on fatigue (Q1) ( 3 [95\% Cl]: 0.17 [0.13-0.22]), back pain (Q2) $(0.51$ [0.46 $0.56])$, peripheral joint pain (Q3) $(0.08$ [0.04-0.12]) and severity of morning stiffness (Q5) (0.08 [0.03-0.13]), and BASFI (0.14 [0.08-0.19]) were independently associated with a higher BAS-G over time (Table 1). In the autoregressive GEE model, all variables except for the BASDAI Q5 showed true longitudinal 
associations with BAS-G. Age, gender and educational level were neither effect modifiers nor confounders.

Table 1. Factors associated with BAS-G over time.

\begin{tabular}{|c|c|c|}
\hline & $\begin{array}{l}\text { Multivariable GEE } \\
\text { model }\end{array}$ & $\begin{array}{l}\text { Multivariable autore- } \\
\text { gressive GEE model } \S\end{array}$ \\
\hline & Coefficient $(95 \% \mathrm{Cl})$ & Coefficient $(95 \% \mathrm{Cl})$ \\
\hline BASDAI Q1 (fatigue, 0-10) & $0.17(0.13 \text { to } 0.22)^{\star}$ & $0.15(0.10 \text { to } 0.20)^{\star}$ \\
\hline BASDAI Q2 (back pain, 0-10) & $0.51(0.46 \text { to } 0.56)^{*}$ & $0.54(0.47 \text { to } 0.60)^{*}$ \\
\hline BASDAI Q3 (peripheral joint pain, 0-10) & $0.08(0.04 \text { to } 0.12)^{*}$ & $0.13(0.08 \text { to } 0.19)^{\star}$ \\
\hline BASDAI Q4 (enthesitis, 0-10) & $0.03(-0.01$ to 0.07$)$ & $0.02(-0.04$ to 0.08$)$ \\
\hline $\begin{array}{l}\text { BASDAI Q5 (severity of morning stiffness, } \\
0-10 \text { ) }\end{array}$ & $0.08(0.03 \text { to } 0.13)^{*}$ & $0.06(-0.01$ to 0.13$)$ \\
\hline $\begin{array}{l}\text { BASDAI Q6 (duration of morning stiffness, } \\
0-10 \text { ) }\end{array}$ & $0.03(-0.01$ to 0.07$)$ & $0.05(-0.01$ to 0.11$)$ \\
\hline SJC28 (0-28) & $0.01(-0.11$ to 0.13$)$ & $0.10(-0.11$ to 0.31$)$ \\
\hline TJC53 (0-159) & $-0.01(-0.02$ to 0.01$)$ & $-0.01(-0.03$ to 0.01$)$ \\
\hline MASES (0-39) & $0.00(-0.02$ to 0.02$)$ & $-0.00(-0.03$ to 0.02$)$ \\
\hline CRP (mg/L) & $0.01(-0.00$ to 0.01$)$ & $0.00(-0.01$ to 0.01$)$ \\
\hline Any EAM (presence vs absence) & $-0.05(-0.21$ to 0.11$)$ & $-0.09(-0.28$ to 0.10$)$ \\
\hline BASFI $(0-10)$ & $0.14(0.08 \text { to } 0.19)^{*}$ & $0.08(0.00 \text { to } 0.16)^{\star}$ \\
\hline BASMI linear (0-10) & $-0.07(-0.16$ to 0.02$)$ & $-0.10(-0.22$ to 0.02$)$ \\
\hline mNY grading $(0-8)$ & $0.01(-0.03$ to 0.06$)$ & $0.06(0.01 \text { to } 0.12)^{\star}$ \\
\hline mSASSS (0-72) & $-0.01(-0.04$ to 0.02$)$ & $0.00(-0.03$ to 0.04$)$ \\
\hline
\end{tabular}

${ }^{*}$ p-value $<0.05$

7) Each joint graded 0-3

§ Adjusted for the outcome (i.e. BAS-G) one year before, in order to disentangle the cross-sectional and longitudinal relationships between outcomes and allow the interpretation of a longitudinal relationship

Conclusion: A higher level of back pain was associated with a worsening of the patient's well-being in early axSpA, as were, though to a lesser extent, higher levels of fatigue, morning stiffness, peripheral joint pain and physical disability. Contextual factors like age, gender and educational level did not have an impact on these relationships. Thus, the previously proposed framework of disease outcomes also applies to patients with early axSpA and to outcomes over time.

References:

[1] Machado, P. ARD 2011.

Disclosure of Interests: Fumio Hirano Paid instructor for: Ono pharmaceuticals, Astellas Pharma Inc, Sumitomo Dainippon Pharma, Chugai Pharmaceutical Co., Ltd., Désirée van der Heijde Consultant of: AbbVie, Amgen, Astellas, AstraZeneca, BMS, Boehringer Ingelheim, Celgene, Cyxone, Daiichi, Eisai, Eli-Lilly, Galapagos, Gilead Sciences, Inc., Glaxo-Smith-Kline, Janssen, Merck, Novartis, Pfizer, Regeneron, Roche, Sanofi, Takeda, UCB Pharma; Director of Imaging Rheumatology BV, Floris A. van Gaalen: None declared, Robert B.M. Landewé Consultant of: AbbVie; AstraZeneca; Bristol-Myers Squibb; Eli Lilly \& Co.; Galapagos NV; Novartis; Pfizer; UCB Pharma, Cecile Gaujoux-Viala: None declared, Sofia Ramiro Grant/research support from: MSD, Consultant of: Abbvie, Lilly, Novartis, Sanofi Genzyme, Speakers bureau: Lilly, MSD, Novartis

DOI: 10.1136/annrheumdis-2020-eular.816

\section{SAT0376 DOES SUPPRESSION OF IL-4 AND IL-13 LEAD TO THE DEVELOPMENT OF NEW ONSET SPONDYLO- ARTHRITIS IN SUSCEPTIBLE PATIENTS?}

C. Hughes ${ }^{1}$, B. Menon ${ }^{1}$, R. Woolf ${ }^{2}$, Z. Willsmore ${ }^{2}$, C. Smith ${ }^{2}$, A. Pink ${ }^{2}$, L. B. Kirkham '. ' 'Guy's and St Thomas' NHS Foundation Trust, Rheumatology, London, United Kingdom; ${ }^{2}$ Guys \& St Thomas Nhs Foundation Trust, St John's Institute of Dermatology, London, United Kingdom

Background: Enthesitis is a key feature of peripheral Spondyloarthritis (SpA). Several pro-inflammatory cytokines including Interleukin-17 and Interleukin-23 are found within the enthesis (1). Dupilumab is a recombinant human monoclonal antibody that inhibits signalling of Interleukin-4 and Interleukin-13, approved for use in patients with moderate- to -severe atopic eczema. Here we describe a cohort of patients with severe atopic eczema who have developed a new peripheral $\mathrm{SpA} /$ enthesitis after receiving Dupilumab.

Objectives: To describe the clinical and imaging details of this cohort.

Methods: All patients in St John's Institute of Dermatology who exhibited new arthralgias on Dupilumab therapy were referred for assessment in Guy's Rheumatology Department. These patients had a focussed history, examination, ultrasound and/or MRI of affected joints and entheseal sites.
Results: To date we have seen 12 patients with a history of new inflammatory peripheral SpA type symptoms following onset of Dupilumab therapy. There were 7 males and 5 females all of whom have longstanding severe atopic Eczema. All patients had raised baseline IgE levels of mainly $>10000$. All patients exhibited a positive response to Dupilumab with a marked improvement in eczema as measured by the EASI score. All patients had normal inflammatory markers and negative immunological screening bloods. Musculoskeletal symptom onse was between 2 and 20 weeks after starting treatment. Typically, these patients had inflammatory symptoms affecting both the small joints and the enthesea sites. 2/12 patients developed inflammatory sounding spinal pain. 2/12 patients had ultrasound evidence of arthritis. 11/12 patients had radiological findings of enthesitis as seen on MRI or ultrasound (power doppler ultrasound signal). 9/12 patients were treated with non-steroidal anti-inflammatories with variable improvement. 1 patient required no treatment and 1 patient received low dose prednisolone.

Conclusion: In our centre approximately 200 patients have received Dupilumab. These musculoskeletal findings have not been reported previously in clinical trials. We hypothesise that the profound inhibition of IL- 4/13 may allow an inflammatory response at the enthesis presenting with a peripheral SpA pattern. IL-4 has been shown to suppress delayed type hypersensitivity reactions (DTHRs) and psoriasis in both human and mice studies (2). These findings and the demonstratation that IL-23 transcription and secretion can be suppressed by IL-4 with resultant reduction in Th17 function (3) may be key factors as to why a SpA type response is seen in certain subjects

\section{References:}

[1] Bridgewood et al. Immunol Rev 2020 [Epub]

[2] Ghoreschi et al. Nat Med. 2003;9:40-6.

[3] Guenova et al. PNAS. 2015;112:2163-8.

Disclosure of Interests: Catherine Hughes Speakers bureau: Lilly, Bina Menon Speakers bureau: Novartis, Richard Woolf: None declared, Zena Willsmore: None declared, Catherine Smith: None declared, Andrew Pink: None declared, L Bruce Kirkham Grant/research support from: Eli Lilly Novartis, Consultant of: Eli Lilly Gilead Janssen Novartis

DOI: 10.1136/annrheumdis-2020-eular.1561

\section{\begin{tabular}{|l|l}
\hline SAT0377 ASSESSMENT OF ANKYLOSING SPONDYLITIS & AST
\end{tabular} ACTIVITY DURING PREGNANCY USING DIFFERENT ACTIVITY INDICES}

O. Krichevskaya ${ }^{1}$, Z. Gandaloeva ${ }^{1}$, T. Dubinina ${ }^{1}$, A. Demina ${ }^{1} .{ }^{1}$ V. A. Nasonova

Research Institute of Rheumatology, Moscow, Russia, Laboratory

of Medical and Social Problems of Rheumatology, Moscow, Russian

Federation

Background: Currently, there is no consensus on the effect of pregnancy on the activity of ankylosing spondylitis (AS). Moreover, in the absence of a pregnancy modified AS activity index, it remains unclear which of the commonly accepted tools can most adequately assesses AS activity during gestation.

Objectives: To assess the dynamics of AS activity during pregnancy, using Bath Ankylosing Spondylitis Disease Activity Index (BASDAI) и Ankylosing Spondylitis Disease Activity Score CRP (ASDAS- CRP).

Methods: The study group included 36 pregnant women with confirmed AS (modified New York criteria, 1984). Patients' mean age was $31.6 \pm 4$.8 years, mean age at AS onset was $21.8 \pm 10.9$, and disease duration - $134.9 \pm 89.3$ months Activity was assessed using BASDAI and ASDAS-CRP at 10-11, 20-21, and 31-32 weeks of pregnancy. BASDAl at the time of conception was assessed retrospectively at the first visit.

Results: BASDAI values in the month of conception and in the trimesters of pregnancy were $2.3 \pm 1.9 ; 2.8 \pm 1.72(p<0.05$ compared to the month of conception); $3.2 \pm 1.9$ and $3.3 \pm 2.1$. Analyzed dynamics of individual BASDAI components is indicative of increasing fatigue from the month of conception $(2[1 ; 3,5])$ and up to $10-11$ weeks of pregnancy $(5[3 ; 7] ; p<0.05)$; the statistical differences with month of conception remained in the II and III trimesters. In the II trimester a tendency to growing back pain (3 [2; 4]) and entheses pain $(2[0 ; 4])$ as compared to the month of conception $(2.5[1 ; 4]$ and $1[0$; $2]$, respectively) was documented. There was an increase in the intensity and duration of morning stiffness in the III trimester $(3.5[1 ; 7]$ and $2.5[1 ; 5]$, respectively) compared to the month of conception $(1.5[0 ; 4]$ and $(2[0 ; 3]$ respectively; $p<0.05)$.

ASDAS-CRP values by trimesters of pregnancy were as follows: $1.9 \pm 0.7 ; 2.3$ \pm 0.9 and $2.2 \pm 0.8$. There was a tendency to increasing CRP levels in the II (8.0 $[2.1 ; 9.6] \mathrm{mg} / \mathrm{l})$ and III trimesters $(7.9[2.0 ; 9.2] \mathrm{mg} / \mathrm{I})$ compared to the I trimester $(5.7[1.6 ; 6.2] \mathrm{mg} / \mathrm{l})$.

Patients' distribution by grades of AS activity is presented in the Table. 